\title{
Reynolds Number Effects on the Flow Around Square Cylinder Based on Lattice Boltzmann Method
}

\author{
T. C. Liu*, Y. J. Ge, F. C. Cao, Z. Y. Zhou, W. Zhang \\ State Key Laboratory for Disaster Reduction in Civil Engineering Tongji University, Shanghai, 200092 \\ China \\ Email: liutcmail@t126.com
}

\begin{abstract}
The Lattice Boltzmann (LB) equation is discussed from the point of molecule kinetic theory at first. Based on the turbulence theory, eddy viscous turbulence model is incorporated into the LB equation to simulate the turbulence flow at high Reynolds number. The flows around square cylinder are simulated in the range of Reynolds number from 10 to $10^{5}$, and the Reynolds number effects on drag. Strouhal number and flow field are investigated in details. Figure 1 and Figure 2 show that the drag and vortexes shedding frequency of square cylinder are dependent on Reynolds numbers. The turbulence LB method is verified by the comparison of present results with those of other numerical methods and experiments.
\end{abstract}

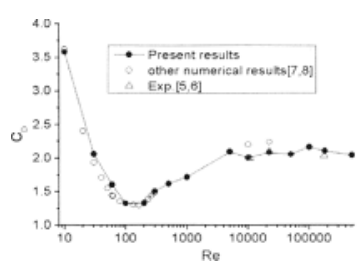

Figure 1: Drag coefficients depending on Re

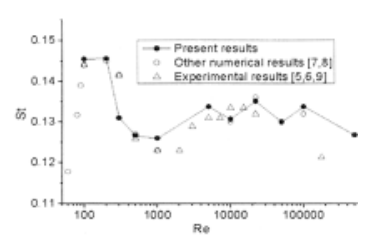

Figure 2: Strouhal number depending on $R e$

\section{REFERENCES}

1. Zhang ZS, Cui GX, Xu XC. Theory and Simulation of Turbulence. Beijing, China, 2005

2. McNamara GR, Zanetti G. Use of the Boltzmann equation to simulate lattice automata. J. Phys. Rev. Let., 1988;61:2332-2335

3. Chen S, Doolen GD. Lattice Boltzmann method for fluid flows. Ann. Rev. Fluid. Mech.. 1998;30:329-364

4. Hudong C, Satheesh K, Steven O, et al. Extended Boltzmann kinetic equation for turbulent flows. Science, 2003;301:633-636

5. Lyn DA, Einva S, Rodi W, et al. A Laser-Doppler Velocimetry Study of Ensemble Averaged Characteristics of the Turbulent Near Wake of a Square Cylinder. J. Fluid Mech., 1995;304:285319

6. Durão D, Heitor M, Pereira J, Measurements of turbulent and periodic flows around a square. cross-section cylinder. J. Exp. Fluid., 1988;6:298-304

7. Franke R, Rodi W. Calculation of vortex shedding past a square cylinder with various turbulence models. in: Proc. 8th Symp. Turbulent Shear Flows, 1991, Tech. Univ. Munich, Springer Berlin. 1991, pp. 189-204

8. Vengadesan S, Nakayama A. Evaluation of LES models for flow over bluff body from engineering application perspective. Sadhana, 2005:30(1):11-20

9. Santosh A., Shyam S. C. A. Entropic lattice Boltzmann simulation of the flow past square cylinder. Int. J. Mod. Phys. C, 2004;15(3):435-445 